RESENHA

Bookreview

\title{
GENDER, SEX AND THE POSTNATIONAL DEFENSE: MILITARISM AND PEACEKEEPING ${ }^{1}$
}

\author{
Katiuscia Moreno Galhera Espósito ${ }^{2}$
}

O Feminismo como teoria das Relações Internacionais (RI) tem obtido um maior espaço em debates e manuais da área apenas contemporaneamente. Seja pela sua marginalização no malestream, seja pela sua entrada tardia na área, o fato é que os Feminismos são quase desconhecidos se comparados com outras correntes. Tratamos agora de Feminismos pois, devido a determinantes múltiplos, não se pode afirmar que exista apenas um tipo de Feminismo em RI. De acordo com J. Ann Tickner e Laura Sjoberg, duas de suas maiores expoentes, em um grande guarda-chuva chamado Feminismo convivem: feminismo liberal, feminismo crítico, feminismo construtivista, feminismo pós-estruturalista e feminismo pós-colonial (2007, págs. 188 a 192, tradução livre). Dada essa pluralidade, o que une todas essas feministas?

O gênero. O gênero nos permite indicar claramente diferenças culturalmente construídas, derivadas em parte da heteronormatividade, que determinam diferenãs sociais. As construções sociais que deram espaço ao malestreamserão um dos principais objetos de análise das feministas, embora não sejam os únicos.

\footnotetext{
${ }^{1}$ KRONSELL, A. Gender, Sex and the Postnational Defense: Militarism and Peacekeeping. Nova York: Oxford University Press, 2012. ISBN: 978-0-19-984606-1

2 Doutoranda em Ciência Política pela UNICAMP. Mestre em Relações Internacionais (RI) pelo Programa San Tiago Dantas (UNESP, UNICAMP e PUC-SP). E-mail: kgalhera@ yahoo.com.br.
} 


\section{Conjuntura Austral}

Ainda de acordo com Tickner e Sjoberg, a agenda de pesquisa feminista em RI pode ser pode ser dividida em duas gerações: a primeira seria amplamente focada na formulação de teorias, e a segunda em "situações empíricas com 'lentes de gênero"" (idem ibidem, p. 188, tradução livre).O "Oxford Studies in Gender and International Relations" éuma série de publicações que fomenta pesquisas feministas junto às acadêmicas de segunda geração, encabeçado pelas próprias Tickner e Sjoberg. Neste espaço nos versaremos sobre um dos livros dessa série: “Gender, Sex and the Post national Defense: Militarism and Peacekeeping"³, de Annica Kronsell.

Diferentemente dos lançamentos que relacionam o papel das mulheres na arena militar com abusos sexuais relacionados ao seu sexo, a intenção de Annica Kronsell neste livro é "explorar a defesa pós-nacional ${ }^{4}$ e suas implicações de gênero" (2012, p. 3 , tradução livre). A pergunta central do livro é: “quão extensamente as relações de gênero tem sido transformadas no contexto de segurança e defesa pós-nacional?" (idem, ibidem, p. 5, tradução livre). Mais especificamente, seu estudo de caso é realizado sobre as Forças Armadas da Suécia. O fundo teórico tomado por Kronsell é o feminismo construtivista, pois ela parte do pressuposto que os valores, crenças e outros determinantes da diferenciação de gênero, materializados em práticas institucionalizadas, podem ser modificados pelos agentes, culminando na clássica relação agente-estrutura do Construtivismo em RI.

Kronsellconcorda que gênero é um princípio organizacional das relações sociais, pois esta é uma “categoria variável de análise que investiga dinâmicas de poder e hierarquias de gênero" (TICKNER apud KRONSELL, 2012, p. 7, tradução livre). Nesse sentido, a autora evidenciará como a questão de gênero é presente desde o recrutamento até as políticas de defesa e segurança.Como a perspectiva da autora é construtivista, ela

\footnotetext{
${ }^{3}$ Os outros livros desta série são: "Enlisting Masculinity: The Construction of Gender in U.S. Military Recruiting Advertising During the All-Volunteer Force", de Melissa Brown; "The Political Economy of Violence Against Women”, de Jacqui True; "Intelligent Compassion: The Women's International League for Peace and Freedom and Feminist Peace" de Catia Cecila Confortini; e From Global to Grassroots: The European Union, Transnational Advocacy, and Combating Violence against Women”, de Celeste Montoya.

${ }^{4}$ Defesa pós-nacional é aquela que "presta menos atenção na defesa do território e mais nas situações de segurança fora de suas fronteiras" (idem ibidem, p. 3).
} 


\section{Conjuntura Austral}

parte da premissa que as performances de gênero inseridas no cotidiano podem ser modificadas, inclusive institucionalmente.

No primeiro capítulo, "Mothers, Soldiersand Nation in the 'Neutral' Defense" a autora demonstra como a defesa na Suécia implica largamente uma política de gênero: por exemplo, os homens podem se alistar voluntariamente em numerosas instituições enquanto as mulheres possuem opções limitadas. O capítulo dois, "Gender, Sexuality, and Institutions of Hegemonic Masculinity" conceitualiza o militar como instituição de hegemonia masculina e traz à tona como as normas de masculinidade hegemônica desenham as possibilidades da "woman-in-arms". As normas de gênero aparecem quando as mulheres e os homossexuais se engajam militarmente (quando a subjetividade das soldadas é confrontada com as normas organizacionais de masculinidade).

No capítulo três, "The Postnational Defense and the Cosmopolitan Military" a autora se versa sobre o caminho sueco rumo à defesa pós-nacional e procura responder se as mudanças podem ser entendidas como cosmopolitanas. A autora conclui que há uma clara ambição de desmilitarização com esse fim, mas que encontra bastante resistência internamente, dada a performance masculina hegemônica de força e violência nas Forças Armadas. A autora também argumenta e aprofunda no próximo capítulo que esse ambiente se tornou mais amigável, por exemplo, com pessoas LGBT. Em "Postnacional Peacekeeping and the Construction of Sex and Gender" é mostrado um exemplo de como a participação das mulheres pode ser positiva nas operações: essas são cruciais quando do contato com mulheres afegãs, pois estas sofrem retaliações se entram em contato com outros homens.

Por fim, no último capítulo, "Defense and Military Governance in the European Union" a autora conclui que a "European Security and Defense Policy" (ESDP) logrou ser pós-nacional em alguns aspectos, faltando normas de equidade de gênero e aderência ao mainstream de gênero.

O livro de Kronsell é um exemplo bastante claro de análise feminista e construtivista empírica de segunda geração. Seu livro é recheado de dados concretos e objetivos que são utilizados para corroborar a existência do malestream em instituições, 


\section{Conjuntura Austral}

criticá-lo e propor alternativas baseadas em equidade de gênero e, por esse motivo, mais eficazes e democráticas.

Resenha recebida dia 10 de julho de 2013. Aprovado em 22 de agosto de 2013. 